\title{
Study of glycaemic control and microalbuminuria in children with type 1 diabetes mellitus
}

\author{
*Ujjwala Mantha ${ }^{1,2}$, Shrikiran Aroor ${ }^{2}$, Pushpa G Kini ${ }^{2}$, Leslie Edward Lewis ${ }^{2}$, Shravan Kanaparthi ${ }^{2,3}$, \\ Ramesh Bhat $\mathbf{Y}^{2}$
}

Sri Lanka Journal of Child Health, 2021; 50(1): 38-42

\begin{abstract}
Background: There is a lacuna in the literature concerning children with type 1 diabetes mellitus (TIDM) and glycaemic control and the occurrence of microalbuminuria in the Indian sub-continent.

Objectives: To study the glycaemic control based on glycated haemoglobin level (HbA1C) and the risk and occurrence of microalbuminuria in children with TIDM.
\end{abstract}

Study design: Prospective observational study.

Participants: Children between the ages of 1-18 years with diabetes of six or more months.

Outcome: Glycaemic control based on $\mathrm{HbA} 1 \mathrm{C}$, occurrence and relation of microalbuminuria to age, sex, HbA1C, hypertension and body mass index (BMI) were studied.

Results: Fifty two (M: $\mathrm{F}=1.25: 1)$ children were included in the study with 48 children completing their second visit (6 months after the 1st visit). Ideal glycaemic control (HbA1C $<7.5 \%$ ) was observed only in $6(12.5 \%)$ children in the study group. No significant relationship was observed between the duration of diabetes and $\mathrm{HbA1C}$ levels $(p=0.64)$. Nineteen $(36.5 \%)$ children had microalbuminuria. No significant differences were found in the sex, age groups, HbA1C and insulin dosage per day between children with and without microalbuminuria. Median BMI was $15.7 \mathrm{~kg} / \mathrm{m}^{2}$ and $13.5 \mathrm{~kg} / \mathrm{m}^{2}$ in the groups with and without microalbuminuria respectively $(\mathrm{p}=0.003)$.

${ }^{1}$ Cloudnine Hospitals, Bangalore, India ${ }^{2}$ Kasturba Medical College, Manipal, Manipal Academy of Higher Education, India, ${ }^{3}$ Narayana Institute of Cardiac Sciences, Bangalore, India

*Correspondence: drujjwala.mantha@gmail.com

https://orcid.org/0000000192316931

(Received on 16 February 2020: Accepted after revision on 20 March 2020)

The authors declare that there are no conflicts of interest

Personal funding was used for the project.

Open Access Article published under the Creative

Commons Attribution CC-BY (C) (i) License
Conclusions: Ideal glycaemic control was observed only in $12.5 \%$ children in the study group. No statistically significant relationship was observed between the duration of diabetes, sex or age and HbAlC levels in the present study. No significant differences were found in the sex, age groups, $\mathrm{HbA} 1 \mathrm{C}$ and insulin dosage per day between children with and without microalbuminuria. However, median BMI had a significant positive association with urinary albumin excretion.

DOI: http://dx.doi.org/10.4038/sljch.v50i1.9400

(Keywords: Diabetes mellitus type 1, child, insulin, albuminuria, glycated haemoglobin A)

\section{Introduction}

Onset of type 1 diabetes mellitus (TIDM) is mainly in the 7-15 year age group, but it can present at any age $^{1}$. Microalbuminuria precedes proteinuria and is a potentially reversible stage of diabetic nephropathy ${ }^{2-4}$. Earlier detection and necessary intervention could change the progression of the disease. This study is conducted to fill the lacunae in the literature concerning children with T1DM and glycaemic control and occurrence of microalbuminuria in the Indian sub-continent.

\section{Objectives}

1. To study glycaemic control in children with TIDM based on glycated haemoglobin level (HbA1C).

2. To study the risk and occurrence of microalbuminuria in children with TIDM.

Method

Study design: Prospective observational

Study period: Case recruitment from 1st October 2016 to 31 st December 2017. Follow-up till 30th June 2018.

Study population: Children between the ages of 1 18 years, attending the paediatric outpatient department (OPD)/medicine OPD or admitted in the department of Paediatrics with a duration of diabetes of 6 months or more.

Inclusion criteria: Age: 1-18 years, TIDM, duration of diabetes: 6 months or more

Exclusion criteria: Children with evident organ system diseases such as connective tissue disorders, 
pre-existing renal diseases and haemolytic anaemias.

Data were collected and history and examination was recorded in a pre-designed proforma. Height, weight, body mass index (BMI), blood pressure, and type, frequency and dosage of insulin received were noted during the hospital visits. Blood samples were collected in plain and fluoridecontaining vacutainers for glycated haemoglobin (analysed using turbidometric inhibitory immunoassay) and blood sugar (RBS/FBS) estimation (Hexokinase method), respectively. Two random, midstream urine samples six months apart, were collected from the children included in the study. Quantitative determination of urine microalbumin was done using a quantitative turbidometric test and creatinine was measured using an automated colorimetric determination based on a modified Jaffe reaction. Urine microalbumin was measured as $\mathrm{mcg} / \mathrm{mg}$ of creatinine; $\geq 30 \mathrm{mcg} / \mathrm{mg}$ creatinine was considered as a cut-off for microalbuminuria ${ }^{3,5}$. In individuals with diabetes mellitus, $\mathrm{HbA} 1 \mathrm{C}$ values $\leq 7.5 \%$ indicated good metabolic control, whilst values $>7.5 \%$ indicated poor metabolic control.

Ethical issues: Ethical approval was obtained from the Institutional Ethics Committee of Kasturba Hospital, Manipal (IEC 937/2016) on 13 December 2016. Written informed consent was obtained from the parents of the participating children.

Statistical analysis: Data were analysed using SPSS 20 software. Mean, and standard deviation were used for data with a normal distribution. Median and IQR $(75,25)$ were used for data with skewed distribution. For categorical data Chisquared test and Fischer's exact test were used. For continuous data Mann Whitney's test was used. $p<$ 0.05 was considered statistically significant.

\section{Results}

A total of 54 children satisfied the inclusion criteria, and of them, two were excluded (One had systemic lupus erythematosus and the other had Wolcott-Rallison syndrome). Thus, 52 children were included in the study group at the first visit. Forty-eight children completed their second visit, 6 months after the $1 \mathrm{st}$ visit. Four children were lost to follow up. No mortality was observed in the study group.

The male: female ratio was 1.25: 1 in the study group. The median age of onset of TIDM was 10.7 years (IQR -13.3, 8). The youngest child at the time of diagnosis was one year five months and the oldest child at diagnosis was 17 years. Thirty two $(66.7 \%)$ and $16(33.3 \%)$ children were $<13$ years and $\geq 13$ of age respectively, at the time of recruitment. The median duration of diabetes at the time of recruitment was 24 months (IQR - 48, 12), $69 \%$ of them being less than 3 years old.

The most common presenting symptoms were polyphagia and polydipsia, observed in 49 (94.2\%) children followed by polyuria in $47(90.3 \%)$ children. Weight loss was observed in 29 (55.7\%) children. Among the group, 19 (36.6\%) children presented with diabetic ketoacidosis (DKA) at initial diagnosis. Median HbA1C level in the study population was $10.4 \%$ (IQR -12.6, 8.8). Range of HbA1C was 6-19.3\%. Median urine microalbuminuria $(\mathrm{mcg} / \mathrm{mg}$ creatinine) was 12.0 (IQR -34.2, 3.8).

Forty $(76.9 \%)$ of the children were on combined short-acting and intermediate-acting insulin, 8 $(15.3 \%)$ were on ultra-short acting and long-acting insulin, and $4(7.8 \%)$ were on intermediate insulin only. No significant difference $(p=0.39)$ was observed in HbA1C levels among males and females. No correlation was observed between the age and $\mathrm{HbA1C}$ levels in the present study. Ideal glycaemic control was observed only in $6(12.5 \%)$ children in the study group. No significant relationship was observed between the duration of diabetes and HbA1C levels in the present study $(p=0.64)$. In the present study, $19(36.5 \%)$ children were found to have microalbuminuria. No significant differences were found in the sex, age groups, $\mathrm{HbA} 1 \mathrm{C}$ and insulin dosage per day between children with and without microalbuminuria (Table 1). Median BMI was 15.7 $\mathrm{kg} / \mathrm{m}^{2}$ and $13.5 \mathrm{~kg} / \mathrm{m}^{2}$ in the groups with and without microalbuminuria respectively $(p=0.003)$.

Majority (93.8\%) of the children had poor glycaemic control, $\mathrm{HbA} 1 \mathrm{C}>7.5 \%$, at the second visit in the present study. Improved glycaemic control was noted in 22 out of 48 children at follow up. However, only 3 out of 48 children had good glycaemic control (HbA1C $\leq 7.5 \%$ ) at follow up. No significant relationship was observed between $\mathrm{HbA} 1 \mathrm{C}$ and urine albumin excretion at the second visit (Table 2).

Median BMI was significantly higher in children with microalbuminuria, with a p-value of 0.04 (Table 2). 
Table 1: Clinical \& biochemical characteristics in children with no microalbuminuria and microalbuminuria

\begin{tabular}{|c|c|c|c|}
\hline Characteristic & $\begin{array}{c}\text { No microalbuminuria } \\
(n=31)\end{array}$ & $\begin{array}{c}\text { Microalbuminuria } \\
(n=17)\end{array}$ & p value \\
\hline $\begin{array}{l}B M I\left(\mathrm{~kg} / \mathrm{m}^{2}\right) \\
\text { Median (IQR75, 25) }\end{array}$ & $13.5(14.5,12.4)$ & $15.7(19.2,14.1)$ & 0.003 \\
\hline $\begin{array}{l}\text { Hypertension } \\
<90^{\text {th }} \text { centile } \\
\geq 90^{\text {th }} \text { centile }\end{array}$ & $\begin{array}{l}23 \\
06\end{array}$ & $\begin{array}{l}14 \\
05\end{array}$ & 0.52 \\
\hline $\begin{array}{l}\text { Insulin dose }(U / \mathrm{kg}) \\
\text { Median (IQR75, 25) }\end{array}$ & $1.06(1.17,0.69)$ & $1.08(1.32,0.78)$ & 0.65 \\
\hline $\begin{array}{l}\text { HbAlC (\%) } \\
\text { Median (IQR75, 25) }\end{array}$ & $10.8(12.6,8.7)$ & $10.1(12.05,8.8)$ & 0.69 \\
\hline $\begin{array}{l}\mathrm{HbA1C} \\
\leq 7.5 \% \\
>7.5 \%\end{array}$ & $\begin{array}{l}03 \\
28\end{array}$ & $\begin{array}{l}03 \\
14\end{array}$ & 0.47 \\
\hline $\begin{array}{l}\text { Urinary albumin excretion }(\mathrm{mcg} / \mathrm{mg}) \\
\text { creatinine } \\
\text { Median }(\mathrm{IQR} 75,25)\end{array}$ & $4(11.05,2.39)$ & $52.8(178.8,31.2)$ & \\
\hline
\end{tabular}

Table 2: Clinical \& biochemical characteristics in children with no microalbuminuria and microalbuminuria at second visit

\begin{tabular}{|l|c|c|c|}
\hline \multicolumn{1}{|c|}{ Characteristic } & $\begin{array}{c}\text { No microalbuminuria } \\
(\boldsymbol{n}=\mathbf{3 1})\end{array}$ & $\begin{array}{c}\text { Microalbuminuria } \\
(\boldsymbol{n}=\mathbf{1 7})\end{array}$ & p value \\
\hline BMI $\left(\mathrm{kg} / \mathrm{m}^{2}\right)$ & $14.9(16.3,13.6)$ & $16.5(20.2,14.1)$ & 0.04 \\
Median (IQR75, 25) & $10(13.05,8.95)$ & $11(12,10.1)$ & 0.65 \\
\hline HbA1C (\%) & 02 & 01 & \\
Median (IQR75, 25) & 27 & 18 & \\
\hline HbA1C & & & \\
$\leq 7.5 \%$ & $4.5(9.65,2.25)$ & $66.5(90,53.3)$ & \\
$>7.5 \%$ & Urinary albumin excretion & & \\
(mcg/mg) creatinine & & & \\
Median (IQR75, 25) & & & \\
\hline
\end{tabular}

\section{Discussion}

The male-female ratio was 1.25: 1 in the study group and this is similar to other studies ${ }^{2,6,7}$. The median age of onset of TIDM in the current study was 10.69 years (IQR -13.32, 8.00). In a study by Alleyn, et $a l^{2}(\mathrm{n}=471$, aged $8-18$ years $)$ mean age was $12.9 \pm 2.3$ years. Omar, et $a l^{8}(\mathrm{n}=40$, aged 2 16 years) reported a mean age of $11.78 \pm 3.83$ years. In the current study, median duration of diabetes at the time of recruitment was 24 months (IQR 48, 12). The duration of diabetes in other studies was higher ${ }^{2,6,8}$.

In our study common presenting symptoms were polyphagia and polydipsia $(94.2 \%)$, polyuria (90.3\%), weight loss (55.7\%) and DKA (36.6\%). In studies conducted by Amritanshu, et $a l^{9}$ and Ibekwe, et $a l^{10}$, polyuria and polydipsia were seen in all the patients while polyphagia was seen less frequently. DKA was seen in 20 out of 43 children (46.5\%) who had microalbuminuria, in the study done by Amritanshu et al. ${ }^{9}$ Median HbA1C level in the study population was $10.4 \%$ (IQR -12.57 , 8.75). Various studies reported mean HbA1C values ranging $8.4-10.3 \%^{2,6,11,12}$. No statistically significant difference was observed in $\mathrm{HbA} 1 \mathrm{C}$ levels among males and females in the present study and this was similar to other studies ${ }^{6,13,14}$. No correlation was observed between the age and HbA1C levels in the present study. Archinkova et $a l^{6}$ and Mohammad, et al. ${ }^{7}$ reported an increase in the $\mathrm{HbA} 1 \mathrm{C}$ levels with age of patient.

Ideal glycaemic control was observed only in 6 $(12.5 \%)$ children in the study group. Good glycaemic control was reported in $39 \%$ by Archinkova et al. ${ }^{6}$ Poor glycaemic control (HbA1C $>7.5 \%$ ), was reported in $61 \%^{6}$ and $45 \%^{7}$ in other studies. There was no statistically significant relationship between the duration of diabetes and HbA1C levels in present study. In studies by Mohammad, et $a l^{7}$ and Niba, et $a l^{12}$, children with poor control had a significantly longer duration of diabetes than those with good control. In a study by Mohammad, et $a l^{7}$ it was found that children with 5 or more years of diabetes were thrice more likely to have poor glycaemic control than those with shorter duration. 
In the present study, $19(36.5 \%)$ children had microalbuminuria. However, no significant differences were found in the sex, age groups, $\mathrm{HbA} 1 \mathrm{C}$ and insulin dosage per day between children with and without microalbuminuria. In a study conducted by Alleyn, et al $23 \%$ had microalbuminuria and $\mathrm{HbA} 1 \mathrm{C}$ was significantly higher in those having microalbuminuria than in those without microalbuminuria $(p=0.03)$. A greater proportion of females among those having persistent microalbuminuria compared to those without microalbuminuria was reported by various studies $^{2,9,15}$. In a study conducted by Patel et $a l^{16}$, males had a higher incidence of microalbuminuria. Hypertension, which modulates progression of vascular complications in diabetes, was found to have varied results on microalbuminuria ${ }^{17-19}$. In our study, median BMI was $15.7 \mathrm{~kg} / \mathrm{m}^{2}$ and $13.5 \mathrm{~kg} / \mathrm{m}^{2}$ in the groups with and without microalbuminuria respectively $(\mathrm{p}=0.003)$. In a study conducted by Alleyn, et $a l^{2}$, there were no statistically significant differences between those with and without microalbuminuria for age, duration of diabetes and BMI.

The authors believe that the sample size in the current study is small and a study with larger sample size is required to draw more firm conclusions. This is a limitation of the study.

\section{Conclusions}

Ideal glycaemic control was observed only in $12.5 \%$ children in the study group. No statistically significant relationship was observed between the duration of diabetes, sex or age and HbA1C levels in the present study. No significant differences were found in the sex, age groups, $\mathrm{HbA1C}$ and insulin dosage per day between children with and without microalbuminuria. However, median BMI had significant positive association with microalbuminuria.

\section{References}

1. Britta M, Nicholas J. Diabetes Mellitus. In:Kliegman, Stanton, St Geme, Schor. Nelson textbook of Paediatrics $20^{\text {th }}$ ed. Philadelphia: Elsevier; 2016; page 276085.

2. Alleyn CR, Volkening LK, Wolfson J, Rodriguez-Ventura A, Wood JR, Laffel LMB. Occurrence of microalbuminuria in young people with type 1 diabetes: importance of age and diabetes duration. Diabetic Medicine 2010; 27:532-7. https://doi.org/10.1111/j.14645491.2010.0 2983.x

PMid: 20536948 PMCid: PMC2966306
3. Perkins BA, Ficociello LH, Silva KH, Finkelstein DM, Warram JH, Krolewski AS. Regression of microalbuminuria in type 1 diabetes. New England Journal of Medicine 2003; 348(23):2285-93. https://doi.org/10.1056/NEJMoa021835 PMid: 12788992

4. Amin R, Widmer B, Prevost AT, Schwarze P, Cooper J, Edge J, et al. Risk of microalbuminuria and progression to macroalbuminuria in a cohort with childhood onset type 1 diabetes: prospective observational study. British Medical Journal 2008; 336(7646): 697701.

https://doi.org/10.1136/bmj.39478.378241

.BE

PMid: 18349042 PMCid: PMC2276285

5. Standards of medical care in diabetes2012. Diabetes Care 2012; 35(Supplement 1):S11--S63.

https://doi.org/10.2337/dc12-s011

PMid: 22187469 PMCid: PMC3632172

6. Archinkova M, Konstantinova M, Savova $\mathrm{R}$, Iotova $\mathrm{V}$, Petrova $\mathrm{C}$, Kaleva $\mathrm{N}$, et al. Glycaemic control in type 1 diabetes mellitus among Bulgarian children and adolescents: the results from the first and the second national examination of HbAlc. Biotechnology and Biotechnology Equipment 2017; 31(6): 1198-203. https://doi.org/10.1080/13102818.2017.13 79360

7. Metwalley K, Abd El-Hafeez H, Mohammad H, Farghaly H, Monazea E. Predictors of glycaemic control in children with type 1 diabetes mellitus in AssiutEgypt. Indian Journal of Endocrinology and Metabolism 2012; 16(5):796. https://doi.org/10.4103/2230-8210.100679 PMid: 23087867 PMCid: PMC3475907

8. Omar MA, Rezk MM, El-Kafoury AA, Kandil MS. Microalbuminuria and glycated haemoglobin in children with type 1 diabetes mellitus. Alexandria Journal of Medicine 2015; 51(1):83-8. https://doi.org/10.1016/j.ajme.2014.04.00 5

9. Amritanshu K, Kumar A, Anand K, Garg $\mathrm{N}$, Banerjee DP. Clinical profile and factors associated with microalbuminuria in type 1 diabetes mellitus in children and adolescents. International Journal of 
Research in Medical Sciences 2015; 3(5):1247-51. https://doi.org/10.5455/23206012.ijrms20 150538

10. Ibekwe M, Ibekwe R. Pattern of type 1 diabetes mellitus in Abakaliki, Southeastern, Nigeria. Paediatric Oncall Journal 2011; 8:59-62.

11. Khanolkar AR, Amin R, Taylor-Robinson D, Viner RM, Warner J, Gevers EF, et al. Ethnic differences in early glycaemic control in childhood-onset type 1 diabetes. BMJ Open Diabetes Research and Care 2017; 5: e000423.

https://doi.org/10.1136/bmjdrc-2017000423

PMid: 28878940 PMCid: PMC5574434

12. Niba LL, Aulinger B, Mbacham WF, Parhofer KG. Predictors of glucose control in children and adolescents with type 1 diabetes: Results of a cross-sectional study in Cameroon. BMC Research Notes 2017; 10(1):1-10. https://doi.org/10.1186/s13104-017-25348

PMid: 28606170 PMCid: PMC5469010

13. McKnight JA, Wild SH, Lamb MJE, Cooper MN, Jones TW, Davis EA, et al. Glycaemic control of Type 1 diabetes in clinical practice early in the 21 st century: an international comparison. Diabetic Medicine 2015; 32(8):1036-50. https://doi.org/10.1111/dme.12676 PMid: 25510978

14. Scottish Study Group for the Care of the Young Diabeteic. Factors influencing glycaemic control in young people with type 1 diabetes in Scotland: a populationbased study (DIABAUD2). Diabetes Care 2001; 24(2):239-44.

https://doi.org/10.2337/diacare.24.2.239

PMid: 11213872

15. Moore THM, Shield JPH. Prevalence of abnormal urinary albumin excretion in adolescents and children with insulin dependent diabetes: the MIDAC study. Archives of Disease in Childhood 2000; 83(3): 239-43.

https://doi.org/10.1136/adc.83.3.239

PMid: 10952644 PMCid: PMC1718460
16. Patel KL, Mhetras SB, Varthakavi PK, Merchant PC, Nihalani KD. Microalbuminuria in non-insulin dependent diabetes mellitus. Journal of the Association of Physicians of India 1999; 47(6):596-601.

17. Schultz CJ, Konopelska-Bahu T, Dalton RN, Carroll TA, Stratton I, Gale EA, et al. Microalbuminuria prevalence varies with age, sex, and puberty in children with type 1 diabetes followed from diagnosis in a longitudinal study. Oxford Regional Prospective Study Group. Diabetes Care 1999; 22(3):495-502.

https://doi.org/10.2337/diacare.22.3.495

PMid: 10097935

18. Schultz CJ, Dalton RN, Neil HAW, Konopelska-Bahu T, Dunger DB, on behalf of the Oxford Regional Prospective Study Group. Markers of renal tubular dysfunction measured annually do not predict risk of microalbuminuria in the first few years after diagnosis of Type I diabetes. Diabetologia 2001; 44(2): 2249.

https://doi.org/10.1007/s001250051603

PMid: 11270680

19. Incerti J, Zelmanovitz T, Camargo JL, Gross JL, de Azevedo MJ. Evaluation of tests for microalbuminuria screening in patients with diabetes. Nephrology Dialysis Transplantation 2005; 20(11): 2402-7.

https://doi.org/10.1093/ndt/gfi074

PMid: 16105865 